\title{
A CLINICAL EXPERIENCE IN ENDOSCOPIC ENDONASAL TRANSSPHENOIDAL HYPOPHYSECTOMY IN SKULL BASE CENTER OF BASRAH
}

\author{
Mustafa Haseeb Atiyah* \& Ahmed M Al-Abbasi ${ }^{\circledR}$
}

*MB,ChB, FIBMS Specialist in ORL-H\&N Surgery, Basrah Teaching Hospital. ${ }^{\circledR}$ MB,ChB, FIBMS, FRCS, Professor of ORL-H\&N Surgery, Department of Surgery, College of Medicine, University of Basrah, Basrah, IRAQ.

\begin{abstract}
Endoscopic Endo-nasal Trans-Sphenoidal (EETS) approach is a minimally invasive technique that has gained increased acceptability for removal of sellar and parasellar tumors.

This prospective study was carried out on 50 patients in Basrah skull base center at Al-Sader Teaching Hospital between August 2017 and July 2019. The technique involved a unilateral, endoscopic, endonasal approach to the sella turcica via an anterior sphenoidotomy which is performed as a joint procedure by a consultant otolaryngologist and a consultant neurosurgeon The most common presenting symptom for pituitary tumor was; headache which present in $80 \%$ (40 patients) of the patients, followed by visual disturbance in $56 \%$ (28 patients). Infertility and hemiparesis are the least symptoms $2 \%$ for each (one patient).

The MRI study of brain and sellar region showed that forty six patients (92\%) was diagnosed as pituitary adenomas and one patient (2\%) have Rathke's cyst and another one have meningioma. Tumor location and extension which was assessed by MRI revealed that $70 \%$ (35 patients) had tumor located in sella with extension to suprasellar region, where only $2 \%$ (one patient) had sellar with supra- and parasellar extension. Eighty percent (40 patients) were virgin cases (not operated before), while only $20 \%$ (10 patients) were revised cases (operated before either open or transsphenoidal). We achieved complete resection of the tumor in $82 \%$ cases (41 patients). The most common method used for reconstruction of the surgical defect was underlay multilayers which was used in $62 \%$ (31 patients), while in 10\%, posterior based middle turbinate flaps were used in reconstruction. We noticed that 3 patients $(6 \%)$ developed significant epistaxis, CSF rhinorrhea in 3 patients (6\%), and unfortunately 3 patients $(6 \%)$ died postoperatively.

In conclusion, this study shows that endoscopic, endonasal, transsphenoidal hypophysectomy is a minimally invasive, effective and safe procedure to remove pituitary tumors.

Key words: Hypophysectomy, Endonasal, Endoscopy, Transsphenoidal.
\end{abstract}

\section{Introduction}

Endoscopic Endo-nasal Transgained increased satisfactoriness for elimination of sellar and para-sellar tumors $^{1}$. Griffith ${ }^{2}$ first described the endonasal approach for removal of pituitary lesions in 1987 as a modification of Hirsch's original approach. Jho et $\mathrm{al}^{3}$ have subsequently popularized the technique.

Feasibility of technique with good surgical and functional outcome has made it popular among ENT and neurosurgeons over the last two decades ${ }^{4}$. Preference of
EETS over the conventional trans-septal and sub-labial approachs resulted from improved visualization and illumination of operative fields and low incidence of related morbidity ${ }^{5}$. Availability of wide angled scopes and high definition cameras allow much better control during surgery and hence significantly better results ${ }^{6}$. This technique has been developed under minimally invasive surgical strategies for patients with pituitary tumors, which eliminates the use of transsphenoid retraction ${ }^{7,8}$. The endoscope represents one of the latest 
innovations because of its ability to have a wider panoramic view ${ }^{9}$ through a narrow surgical corridor and its ability to provide angled 'close up view' to detect eventual tumor remnants ${ }^{10}$.

\section{Patients and methods}

A prospective study was carried out from August 2017 to June 2019 at Basrah skull base center in Al-Sader Teaching Hospital which included 50 patients as shown in table I. A detailed history, clinical examination and investigations were performed according to a predesigned questionnaire to inquire about information related to age, gender, residence, occupation, and symptomatology.

All patients scheduled for pituitary surgery underwent radiological evaluation (CT scan of nose and PNS and MRI of brain), endocrine assessment by endocrinologist, visual field tests pre- and postoperatively by ophthalmologist. Preoperative and postoperative nasal endoscopic examination was also a part of routine assessment done by ENT surgeon. All patient were evaluated by neurosurgeon for full neurological examination pre and postoperatively.

Endoscopic endonasal transsphenoidal surgery took place under general orotracheal anesthesia, the oropharyngeal region being well packed with a gauze roll to prevent postoperative blood and fluid aspiration. Intraoperative antibiotic treatment was with an intravenous third generation cephalosporin. The patient was positioned to be supine with slight elevation of the head.

The surgery has four stages (nasal stage, sphenoid stage and reconstruction done by otolaryngologist, while sellar stage by neurosurgeon). Surgery commenced with endoscopic identification of the middle and superior turbinates. The middle turbinate and the sphenoid ostium lead the surgeon to the sphenoid sinus. Enlargement of the sphenoid ostium was the next step followed by identification of the sphenoid sinus. The same procedure was performed through the other nostril, that is, a "binostril approach". After enlargement of both sphenoid ostia and removal of sphenoid septum or septa, identification of the structures in the sella region was done. The neurosurgeon now takes the work and completes the sellar stage with tumor removal. After complete removal of tumor, reconstruction stage done by otolaryngologist by various types depends on the state of surgical defect. Sphenoid pack and bilateral anterior nasal pack was put, patient monitored in ICU for the first 24hrs. Nasal pack removed after $48 \mathrm{hrs}$, and sphenoid pack after 5 days. Analgesia and antibiotics were routinely prescribed for the patients postoperatively.

Table I. Demographic characteristics

\begin{tabular}{|l|c|c|c|c|c|c|}
\hline \multirow{2}{*}{} & \multicolumn{4}{|c|}{ Gender } & \multicolumn{2}{c|}{ Total } \\
\cline { 2 - 7 } & \multicolumn{2}{|c|}{ Male } & \multicolumn{2}{c|}{ Female } & \multicolumn{2}{c|}{} \\
\cline { 2 - 7 } & Frequency & $\%$ & Frequency & $\%$ & Frequency & $\%$ \\
\hline $1-10$ years & 0 & 0 & 1 & $2 \%$ & 1 & $2 \%$ \\
\hline $11-20$ years & 6 & $12 \%$ & 1 & $2 \%$ & 7 & $14 \%$ \\
\hline 21-30 years & 1 & $2 \%$ & 10 & $20 \%$ & 11 & $22 \%$ \\
\hline 31-40 years & 6 & $12 \%$ & 7 & $14 \%$ & 13 & $26 \%$ \\
\hline 41-50 years & 5 & $10 \%$ & 9 & $18 \%$ & 14 & $28 \%$ \\
\hline above 50 years & 3 & $6 \%$ & 1 & $2 \%$ & 4 & $8 \%$ \\
\hline Total & 21 & $42 \%$ & 29 & $58 \%$ & 50 & $100 \%$ \\
\hline
\end{tabular}




\section{Results}

The most common presenting symptoms for the patients enrolled in this study was; headache which was present in $80 \%$ (40 patients), while infertility and hemiparesis were the least symptoms $2 \%$ for each (one patient) as shown in figure 1.

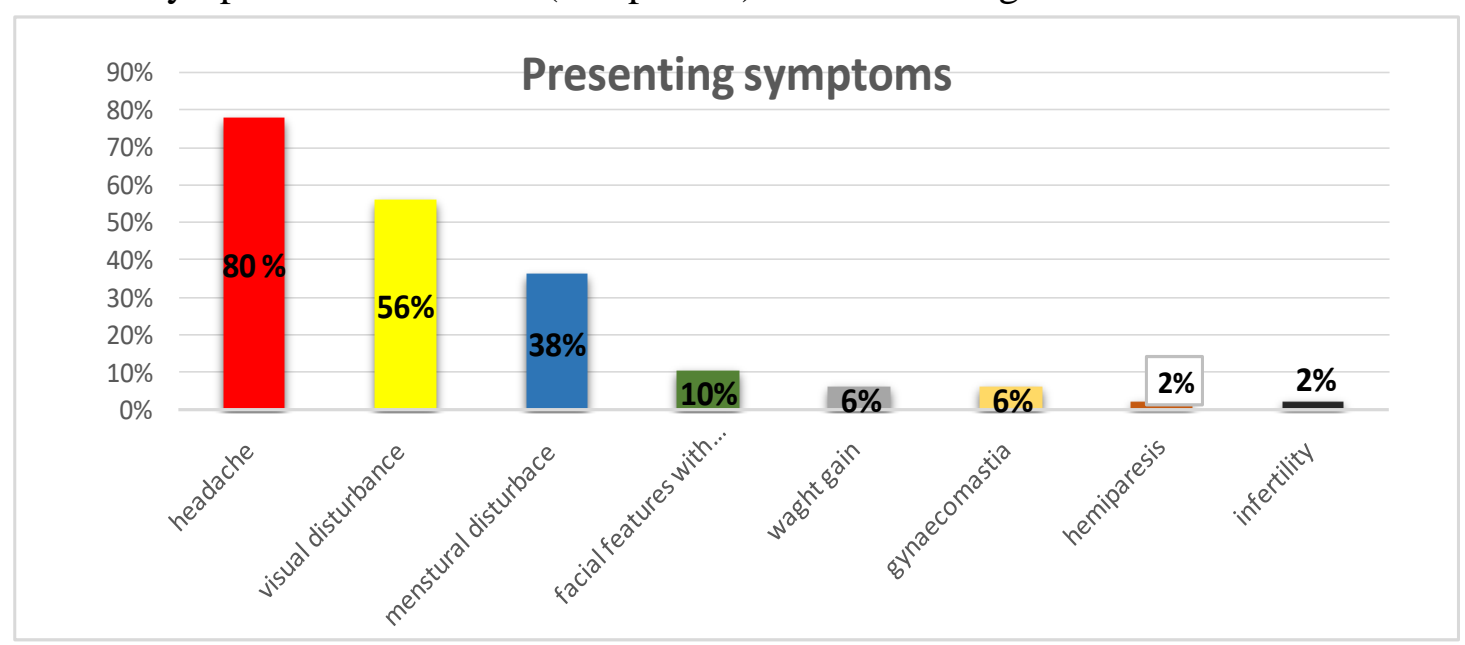

Figure 1: Clinical presentation of patients

Tables II \& III shows the diagnostic characteristics and the location of pituitary tumor detected by MRI preoperatively. Forty six patients (92\%) diagnosed as pituitary adenomas. One patient have Rathke's cyst and another one have meningioma. We operate on $80 \%$ (40 patients) virgin cases and achieved $82 \%$ complete surgical resection of tumor in all the cases.

Table II: The MRI characteristics of the tumors

\begin{tabular}{|l|l|l|}
\hline Type & Frequency & $\%$ \\
\hline Pituitary adenoma & 42 & $84 \%$ \\
\hline Pituitary adenoma with apoplexy & 4 & $8 \%$ \\
\hline Craniopharyngiomas & 2 & $4 \%$ \\
\hline Rathke's cyst & 1 & $2 \%$ \\
\hline Meningioma & 1 & $2 \%$ \\
\hline Total & 50 & $100 \%$ \\
\hline
\end{tabular}

Table III: The location of the tumors

\begin{tabular}{|l|l|l|}
\hline Location of the tumor & Frequency & $\%$ \\
\hline Sella & 11 & $22 \%$ \\
\hline Sellar with suprasellar extension & 35 & $70 \%$ \\
\hline Sellar with parasellar extension & 3 & $6 \%$ \\
\hline Sellar with supra- and parasellar extension & 1 & $2 \%$ \\
\hline Total & 50 & $100 \%$ \\
\hline
\end{tabular}

Different methods with various materials for skull base repair was used as showed in table IV. The most common method used is underlay multilayers which used in $62 \%$ (31 patients), while in $10 \%$ posterior based middle turbinate flap were used in reconstruction. The mean duration period of follow up was 3 to 12 months. We found 
that 3 patients $(6 \%)$ developed significant epistaxis, 3 patients $(6 \%)$ CSF rhinorrhea, and unfortunately 2 patients (4\%) died postoperatively.

Table IV: Types of repair

\begin{tabular}{|l|l|l|}
\hline Repair types & Frequency & Percentage \\
\hline Underlay multilayers & 31 & $62 \%$ \\
\hline Underlay multilayers with septal flap and fat & 14 & $28 \%$ \\
\hline Middle turbinate flap & 5 & $10 \%$ \\
\hline Total & 50 & $100 \%$ \\
\hline
\end{tabular}

\section{Discussion}

Pituitary tumors are the most commonly encountered intracranial neoplasms, while most recent series estimate the prevalence of clinically apparent pituitary lesions to comprise approximately $10-15 \%$ of all intracranial lesions ${ }^{11}$. Many surgical approaches to sella are used, but the endoscopic trans-sphenoidal approach become a standard procedure to access sella and pituitary region ${ }^{4,12}$.

Traditionally, pituitary surgery comes under the realm of neurosurgeon but introduction of EETS approach to sella has made Otorhinolaryngologist an active partner in surgical management ${ }^{10}$.

The most common presenting symptoms for patient with pituitary tumors in our study was headache in $80 \%$ (40 patients), followed by visual disturbance $56 \%$ (28 patients), and the least on was infertility $2 \%$ (one patient). This results is comparable with Hanuman et $\mathrm{al}^{13}$, Yildirim et $\mathrm{al}^{14}$ and not match with Singh et $\mathrm{al}^{15}$ in which visual disturbance is the most common presenting symptoms followed by headache in his review. The acceptable explanation for occurrence of headache and visual disturbance in pituitary tumors is, they are mostly due to mass effect of tumor to surrounding structures.

In our study, $82 \% \quad$ (41 patients) underwent complete tumor resection while $18 \%$ (9 patients) were incomplete. This may be due to learning curve as in early cases, with improve surgical skills and with increasing experience the tumor resection become complete and inability to access tumor in those patients has wide intracranial extensions. These results are encouraging and much higher than those with Jho et $\mathrm{al}^{16}(70 \%)$, Singh et $\mathrm{al}^{15}$ (64\%), Hanuman et $\mathrm{al}^{13}(64 \%)$, and nearly same as S Kumar et $\mathrm{al}^{17}(86 \%)$, but less than Varshney et al ${ }^{10}(90 \%)$, and Dehdashti et al ${ }^{18}(90 \%)$ as they used image guided endoscopy (neuronavigation) during the procedure which improve visualization and decrease complications.

Different types of reconstruction for skull base surgical defect were used. The most common type is multilayers repair in $62 \%$ (31 patients), multilayer with septal flap and fat used in 28\% (14 patients) when large defect of sella seen after tumor removed and CSF leak occur. In 5 patients $(10 \%)$ we use posterior based middle turbinate flap for repair.

The complication rate in this study is comparable to previous studies indicating low complication rate for EETS which make it as safe procedure in comparable to other approaches. The most common encountered one was CSF leak found in 6\% (3 patients). These results are lower than other study of Kumar et $\mathrm{al}^{17}(11 \%)$, Hanuman et $\mathrm{al}^{13}(12 \%)$, Singh et $\mathrm{al}^{15}$ $(8 \%)$, and higher than Varshney et $\mathrm{al}^{10}$ (3.5\%), Jho et $\mathrm{al}^{16}(4 \%)$, and Cappabianca et $\mathrm{al}^{19}(2 \%)$. These results are unrelated to type of closure of skull base defect. Among these three patients, one patient needed another surgical intervention to seal the leak, the remaining resolved on conservative 
measures. Epistaxis is also encountered in 6\% (3 patients), this results match with Cappabianca et $\mathrm{al}^{19}$, Cavallo et $\mathrm{al}^{20}$, but more than Kumar et $\mathrm{al}^{17}(0.7 \%)$. Diabetes incipidus found in $2 \%$ (one patient). this result is comparable to Dehdashti et $\mathrm{al}^{18}$, Charalampaki et $\mathrm{al}^{21}$ and much lower than Varshney et $\mathrm{al}^{10}(7 \%)$ and Singh et $\mathrm{al}^{15}(8 \%)$. The mortality rate was $4 \%(2$ patients) in our study, they died during the first week postoperatively. First one died in the 3rd postoperative day in ICU due to sever pneumocephalus, second one died in 5th postoperative day due to meningitis. These results are higher than other studies, Dehdashti et $\mathrm{al}^{18}$, Charalampaki et $\mathrm{al}^{21}$ and Varshney et $\mathrm{al}^{10}$, which showed no mortality in their studies.

Conclusion:

The frequency of pituitary tumors varies greatly according to age and gender. The various tumor types have their peak occurrence in distinctly different age groups and differ greatly in their femaleto-male ratios. The EETH is safe, effective and has a low complication rate. Postoperative assessment showed encouraging symptomatic improvement and significant hormonal normalization.

\section{References}

1. Cappabianca P, Alfieri A, Colao A, Ferone D, Lombardi G, De Divitiis E. Endoscopic endonasal transsphenoidal approach: an additional reason in support of surgery in the management of pituitary lesions. Skull base surgery. 1999;9(02):109-17.

2. Griffith HB, Veerapen R. A direct transnasal approach to the sphenoid sinus. Journal of neurosurgery. 1987;66(1):140-2. 3. Jho H-D, Carrau R. Endoscopy assisted transsphenoidal surgery for pituitary adenoma. Acta neurochirurgica. 1996;138(12):1416-25.

4. Chone CT, Sampaio MH, Sakano E, Paschoal JR, Garnes HM, Queiroz L, et al. Endoscopic endonasal transsphenoidal resection of pituitary adenomas: preliminary evaluation of consecutive cases. Brazilian journal of otorhinolaryngology. 2014;80(2):146-51.

5. Van Lindert EJ, Ingels K, Mylanus E, Grotenhuis JA. Variations of endonasal anatomy: relevance for the endoscopic endonasal transsphenoidal approach. Acta neurochirurgica. 2010;152(6):1015-20.

6. Al Abbasi A: Functional Endoscopic Sinus Surgery. Basrah Journal of Surgery. 2020;Vol.26, No.2. P13.

7. Boxerman JL, Rogg JM, Donahue JE, Machan JT, Goldman MA, Doberstein CE. Preoperative MRI evaluation of pituitary macroadenoma: imaging features predictive of successful transsphenoidal surgery. American Journal of Roentgenology. 2010;195(3):720-8.

8. Nie S, Li K, Huang Y, Zhao J, Gao X, Sun J. Endoscopic endonasal transsphenoidal surgery for treating pituitary adenoma via a sub-septum mucosa approach. International journal of clinical and experimental medicine. $2015 ; 8(4): 5137$.

9. Al-Asadi SZ, Al-Abbasy AM. Efficacy of diode laser transcanalicular dacryocystorhinostomy for the treatment of acquired nasolacrimal duct obstruction. Basrah Journal of Surgery. 2011;17(2):64-8.

10. Varshney S, Gupta C, Bansal K, Bist S, Bhagat S. Endoscopic trans-nasal trans-sphenoidal (TNTS) approach for pituitary adenomas: our experience. Indian Journal of Otolaryngology and Head \& Neck Surgery. 2013;65(2):308-13.

11. Chanson P, Salenave S. Acromegaly. Orphanet Journal of Rare Diseases. 2008:3(1):17.

12. Choe J-H, Lee K-S, Jeun S-S, Cho J-H, Hong Y-K. Endocrine outcome of endoscopic endonasal transsphenoidal surgery in functioning pituitary adenomas. Journal of Korean Neurosurgical Society. 2008;44(3):151.

13. Prajapati HP, Jain SK, Sinha VD. Endoscopic versus microscopic pituitary adenoma surgery: An institutional experience. Asian journal of neurosurgery. 2018;13(2):217.

14. Yildirim AE, Sahinoglu M, Ekici I, Cagil E, Karaoglu D, Celik H, et al. Nonfunctioning pituitary adenomas are really clinically nonfunctioning? clinical and endocrinological symptoms and outcomes with endoscopic endonasal treatment. World neurosurgery. 2016;85:185-92.

15. Singh A, Grewal SS, Kumar N. Endoscopic Endo-Nasal Trans-Sphenoidal Excision of Pituitary Tumors: An Institutional Experience. Indian Journal of Otolaryngology and Head \& Neck Surgery. 2018;70(1):98-101.

16. Jho H-D, Carrau RL. Endoscopic endonasal transsphenoidal surgery: experience with 50 patients. Journal of neurosurgery. 1997;87(1):44-51.

17. Kumar S, Darr A, Hobbs C, Carlin W. Endoscopic, endonasal, trans-sphenoidal hypophysectomy: retrospective analysis of 171 procedures. The Journal of Laryngology \& Otology. 2012;126(10):1033-40.

18. Dehdashti AR, Ganna A, Karabatsou K, Gentili F. Pure endoscopic endonasal approach for pituitary adenomas: early surgical results in 200 patients and comparison with previous microsurgical series. Neurosurgery. 2008;62(5):1006-17.

19. Cappabianca P, Alfieri A, Colao A, Cavallo L, Fusco M, Peca C, et al. Endoscopic endonasal transsphenoidal surgery in recurrent and residual pituitary adenomas. min-Minimally Invasive Neurosurgery. 2000;43(01):38-43.

20. Cavallo L, Briganti F, Cappabianca P, Maiuri F, Valente V, Tortora F, et al. Hemorrhagic vascular complications of endoscopic transsphenoidal surgery. min-Minimally Invasive Neurosurgery. 2004;47(03):145-50.

21. Charalampaki P, Reisch R, Ayad A, Conrad J, Welschehold S, Perneczky A, et al. Endoscopic endonasal pituitary surgery: surgical and outcome analysis of 50 cases. Journal of clinical neuroscience. 2007;14(5):410-5. 